Consequently the female to male ratio fell from $2 \cdot 9$ to $2 \cdot 3$. In the present study the ratio fell from 2.9 to 2.4 over a similar period.

Two incidental findings in this study deserve comment. Firstly, cholecystolithotomy virtually disappeared as an operation for gall stones in the 1950s and 1960s, presumably because of the high recurrence rate when the gall bladder is left in situ. Most recurrences occur within the first few years (Norrby and Schonebeck, 1970), so it is unlikely that a significant number of patients were counted twice in the present study. Secondly, the 40-49 decade was at no time the commonest decade for undergoing cholecystectomy, which further discredits the old jingle that the typical gall stone sufferer is fair, fat, fertile, and forty.

Requests for reprints should be addressed to Dr. K. W. Heaton, University of Bristol Department of Medicine, Royal Infirmary, Bristol 2.

\section{References}

Andersson, A., Bergdahl, L., and Boquist, L. (1971). American fournal of Surgery, 122, 3 .

Bouchier, I. A. D., Rhodes, K., and Brien, M. (1968). Scandinavianfournal of Gastroenterology, 3, 299.

Edlund, Y., and Olsson, O. (1956). Acta Chirurgica Scandinavica, 111, 481.

General Register Office (1961-70). Reports on Hospital In-patient Enquiry, 1958-67. London, H.M.S.O.

Gordon, I. R. S. (1953). Quarterly Fournal of Medicine, 46, 261.

Nilsson, S. (1966). Acta Chirurgica Scandinavica, 132, 275.

Norrby, S., and Schonebeck, J. (1970). Acta Chirurgica Scandinavica, 136, 711.

Sternby, N. H. (1968). Acta Pathologica et Microbiologica Scandinavica, Suppl. No. 194.

van der Linden, W. (1961). Acta Chirurgica Scandinavica, Suppl. No. 269.

van der Linden, W., and Rentzhog, U. (1960). Acta Chirurgica Scandinavica, $119,489$.

\title{
Insulin, Glucose, and Potassium in the Treatment of Congestive Heart Failure
}

\author{
S. P. ALLISON, C. J. MORLEY, C. J. BURNS-COX
}

British Medical fournal, 1972, 3, 675-678

\section{Summary}

A daily infusion of $500-1,000 \mathrm{ml}$ of $50 \%$ glucose containing 100-120 units of soluble insulin and 100-120 $\mathrm{mEq}$ of potassium chloride per litre was given to six patients suffering from hyponatraemia and congestive cardiac failure resistant to digoxin and diuretic therapy. In two patients there was no response, but four showed a striking improvement with a sodium and water diuresis, a rise in plasma sodium level, and in two cases a reversion from atrial fibrillation to sinus rhythm. It is suggested that insulin, glucose, and potassium given by the intravenous route in adequate dosage forms a useful adjunct to the management of severe congestive heart failure.

\section{Introduction}

Insulin has been said to be useful in the treatment of congestive heart failure (Flear, 1966; Sodi-Pallares et al., 1969), but this has been obscured by the controversy over its use after myocardial infarction (Medical Research Council Working Party, 1968). Sodi-Pallares et al. (1969) pointed out that in studies which purported to test their insulin, glucose, and potassium regimen, the dose and route of administration were different from those which they recommended. Flear ascribed its effect to enhancement of the sodium pump and to reversal of the high intracellular sodium content which poisons myocardial activity. The effect of insulin and glucose in burnt patients has been reported (Hinton and Allison, 1969; Hinton et al., 1971). In these patients a large sodium diuresis, a rise in plasma sodium level, and lower urinary nitrogen and potassium losses were found. In view of the similarity between the electrolyte abnormalities in burnt patients and those in severe congestive heart failure it was

Department of Medicine, Bristol Royal Infirmary

S. P. ALLISON, M.D., M.R.C.P., Wellcome Senior Research Fellow (At present: Consultant Physician, Nottingham General Hospital)

Frenchay Hospital, Bristol

C. J. MORLEY, M.B., M.R.C.P., Senior House Officer

C. J. BURNS-COX, M.D., M.R.C.P., Consultant Physician decided to assess the value of the insulin, glucose, and potassium regimen in the cardiac patients of our own hospitals, selecting patients in whom conventional therapy had failed.

\section{Patients and Methods}

Six patients were studied, each of whom had been referred by a consultant cardiologist because of failure to respond to conventional treatment with digoxin and diuretics. They were all suffering from severe congestive cardiac failure and hyponatraemia.

The insulin, glucose and potassium regimen was similar to that described previously (Hinton et al., 1971). A total of $500-1,000 \mathrm{ml}$ of $50 \%$ glucose containing 100-120 units of soluble insulin/l. and $100-200 \mathrm{mEq}$ of potassium chloride/l. was given daily. The mixture was infused at $40 \mathrm{ml} / \mathrm{hr}$ through a central venous catheter and flushed in with $5 \%$ glucose via a three-way tap. All urine samples were tested for sugar by the Clinitest method, and frequent measurements of blood glucose were made with Dextrostix. The amount of insulin was then adjusted to obtain up to $1 \%$ glycosuria with a blood glucose between 100 and $150 \mathrm{mg} / 100 \mathrm{ml}$. Twice-daily measurements of plasma potassium were made and the potassium chloride content of the infusion was adjusted accordingly. Continuous E.C.G. monitoring was carried out with an oscilloscope and a careful watch maintained for any rhythm changes. The patients were weighed at least once a day and fluid balance was charted. Estimations of urea, sodium, potassium, chloride, and bicarbonate were made in sequential 24-hour urine collections and in twice-daily plasma samples by using autoanalyser techniques. Urine volumes were measured two-hourly in Case 1 (see Fig. 1) and 12-hourly in Cases 2 to 4 in order to correlate changes in urine volume, weight, and plasma sodium concentration with insulin and glucose infusions over short periods of time.

\section{Results}

Two patients derived no benefit from the treatment and died a few days later. The other four showed a striking response in terms of sodium and water diuresis, with a rise in plasma sodium concentration. Two of these showed a reversal from atrial fibrillation to sinus rhythm. 

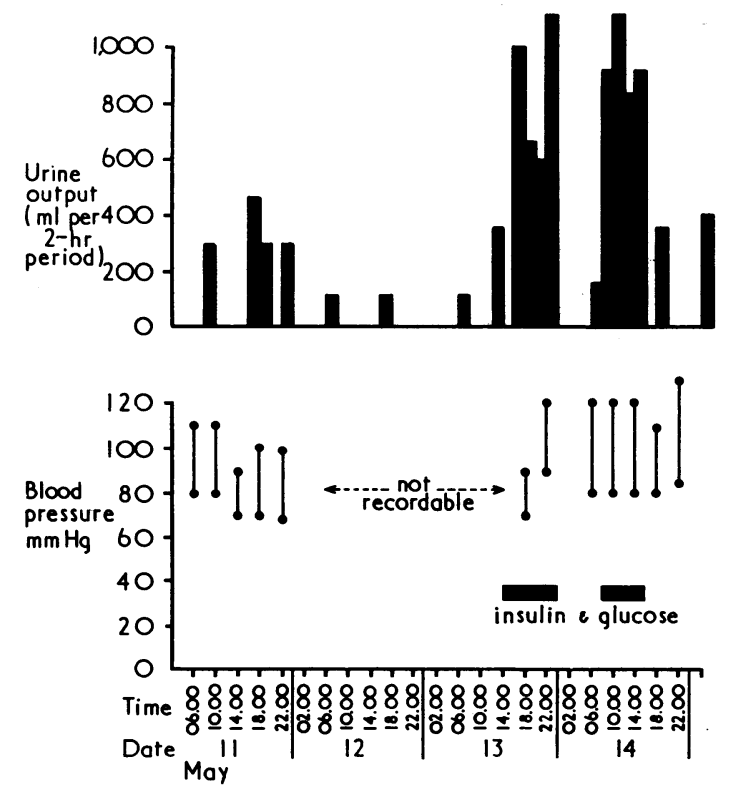

FIG. 1-Case 1. Effect of insulin and glucose infusion on urine output (measured two-hourly) and blood pressure at varying times of the day.

CASE 1

A 54-year-old man with severe mitral incompetence and cardiac enlargement was admitted to hospital for cardiac surgery two months after cardiac catheterization. He was found to have deteriorated so much as to be unfit for operation. The jugular venous pressure was $+10 \mathrm{~cm}$ relative to the sternal angle and there was dyspnoea, cyanosis, jaundice, and gross leg oedema. In spite of digoxin $0.5 \mathrm{mg}$, frusemide $80 \mathrm{mg}$, and, later, ethacrynic acid 100 $\mathrm{mg}$ daily he continued to deteriorate, so that five days after admission he was moribund, with blood pressure unrecordable by the cuff method, radial pulses impalpable, urine output $200 \mathrm{ml} / 24$ $\mathrm{hr}$, plasma urea $120 \mathrm{mg} / 100 \mathrm{ml}$, sodium $126 \mathrm{mEq} / 1$., potassium 6.9 $\mathrm{mEq} / 1$., chloride $83 \mathrm{mEq} / 1$., bicarbonate $23 \mathrm{mEq} / 1$., and serum bilirubin $3.5 \mathrm{mg} / 100 \mathrm{ml}$. Insulin, glucose, and potassium infusion was begun (see Figs. 1 and 2). Within an hour the cardiac rhythm had changed from atrial fibrillation to sinus rhythm and the blood pressure had risen to $120 / 90 \mathrm{~mm} \mathrm{Hg}$. His clinical state improved dramatically and a massive sodium and water diuresis ensued, with a rise in the urine sodium/potassium ratio. Plasma urea and potasium levels fell to normal and plasma sodium rose from 124 to $131 \mathrm{mEq} / 1$. After stopping the infusion the improvement was maintained, and a successful mitral valve replacement was performed four weeks later. He remained well nine months after operation.
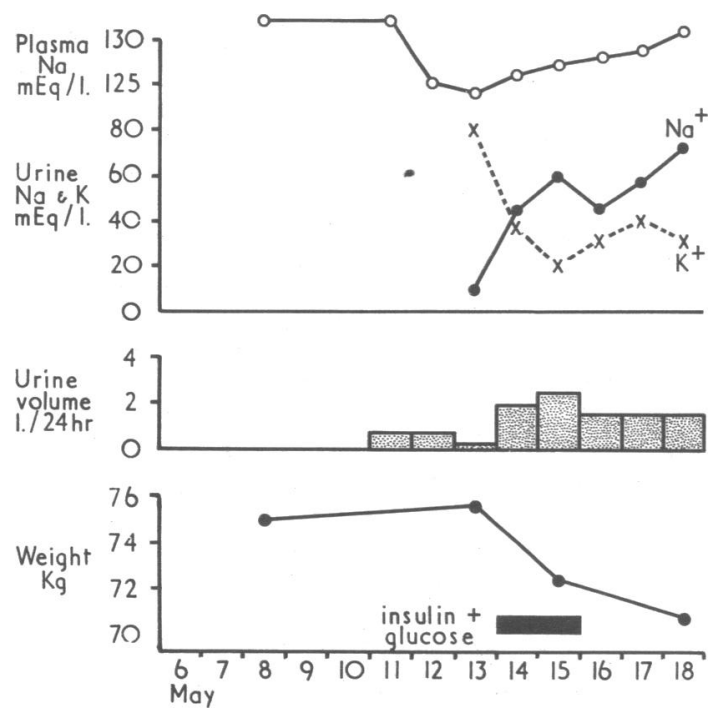

FIG. 2-Case 1. Changes in weight, urine volume (per $24 \mathrm{hr}$ ), and plasma and urine electrolyte values in response to insulin and glucose infusion.

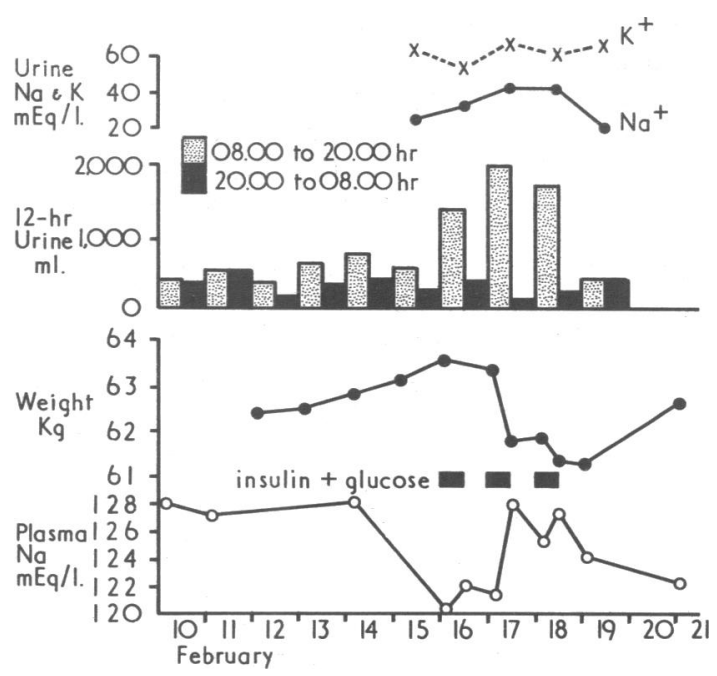

FIG. 3-Case 2. Changes in weight, urine output, and electrolyte levels in plasma and urine in response to insulin and glucose infusion.

CASE 2

A woman, aged 49, had chronic rheumatic heart disease with mitral and tricuspid incompetence. In January 1972 the mitral valve was replaced by a Starr-Edwards prosthesis. Postoperatively she remained ill with confusion, congestive failure, and a persistent hypokalaemic alkalosis in spite of potassium chloride supplements of up to $130 \mathrm{mEq}$ daily given intravenously or by mouth. She became unresponsive to frusemide $120 \mathrm{mg}$ daily, and on 13 February ethacrynic acid $100 \mathrm{mg}$ daily was substituted. She continued to accumulate oedema, however, and on 16 February $50 \%$ glucose infusion, containing 120 units of soluble insulin and 200 mEq of potassium chloride/1. was begun. This was given between 10.00 and 16.00 hours each day. Ethacrynic acid was continued and no other change in treatment was made. A brisk response was seen (Fig. 3).

The infusion resulted in a change from atrial fibrillation to sinus rhythm. There was an increase in urine volume and in urine sodium concentration during the period of administration, with a weight loss of $2 \mathrm{~kg}$ over the three days of treatment. A rise in plasma sodium concentration occurred. On the second day it rose from 121 to $128 \mathrm{mEq} / 1$. during the six-hour period of treatment. At the same time there was a weight loss of $1.6 \mathrm{~kg}$ and a

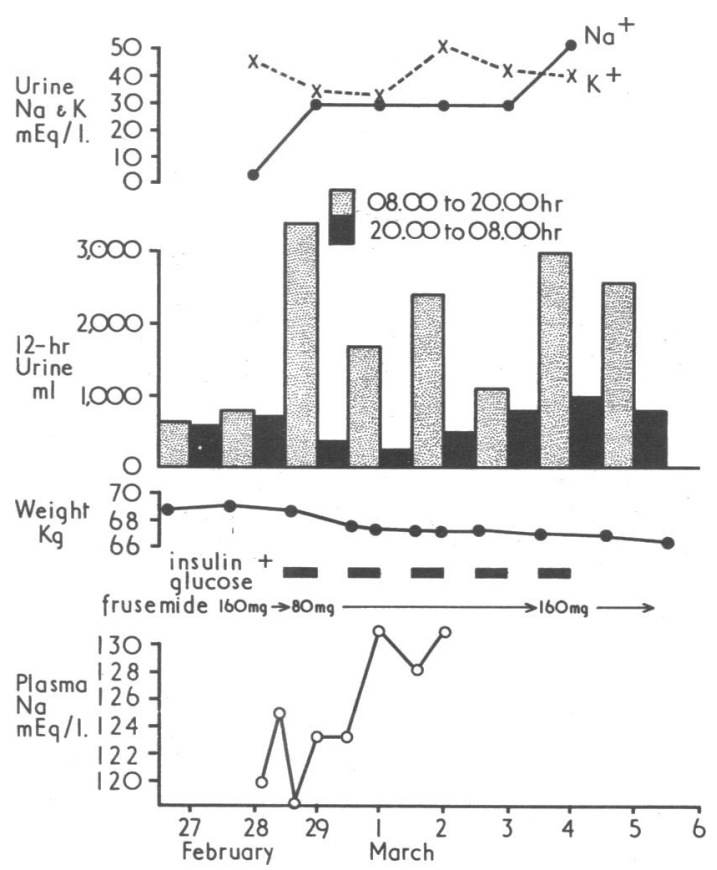

FIG. 4-Case 3. Response to infusion of insulin and glucose. 
negative sodium balance of $84 \mathrm{mEq}$. An $80 \mathrm{mEq}$ dose of potassium in the form of potassium chloride was given daily by mouth during the seven days before the infusion, but the plasma potassium had fallen to $2.5 \mathrm{mEq} / 1$. and the plasma bicarbonate had risen to $40 \mathrm{mEq} / 1$. During the three days of the glucose and insulin infusion the mean daily intake of potassium chloride was $155 \mathrm{mEq}$. A positive balance of $110 \mathrm{mEq}$ of potassium was obtained with a rise in plasma potassium to $3.3 \mathrm{mEq} / 1$. and a fall in plasma bicarbonate to $36 \mathrm{mEq} / 1$. In spite of her temporary improvement she deteriorated again two weeks later, at which time a further insulin, glucose, and potassium infusion proved ineffective. At necropsy an adrenal tumour was found of the aldosterone secreting type. This may have accounted for the persistent hypokalaemic alkalosis.

\section{CASE 3}

A man, aged 45, was admitted to hospital with congestive heart failure, having sustained a myocardial infarction three years previously. Seven months before admission he had several attacks of left ventricular failure requiring treatment with digoxin and diuretics. On admission he was extremely ill and orthopnoeic, with pulmonary oedema, a pulse rate of $130 / \mathrm{min}$, and a gallop rhythm. The jugular venous pressure was raised $6 \mathrm{~cm}$, the liver was enlarged, he was jaundiced, and there were signs of mitral incompetence. Frusemide was increased to $160 \mathrm{mg}$ daily and spironolactone was added. Despite this his condition deteriorated. Plasma sodium fell from 134 to $120 \mathrm{mEq} / \mathrm{l}$, plasma urea rose to $70 \mathrm{mg} / 100 \mathrm{ml}$, plasma potassium remained at $4.0 \mathrm{mEq} / 1$, and serum bilirubin was $6 \mathrm{mg} / 100 \mathrm{ml}$. A $100 \mathrm{ml}$ dose of $4.5 \%$ saline given intravenously evoked no response. Insulin, glucose, and potassium infusion was then given for 12 hours a day for five days. In spite of reducing his frusemide to $80 \mathrm{mg}$ daily he had a substantial sodium and water diuresis (see Fig. 4). Plasma sodium rose from 123 to 131 $\mathrm{mEq} / \mathrm{l}$. On 4 March the dose of frusemide was again increased to $160 \mathrm{mg}$ daily and a further diuresis took place. The patient felt much better and the improvement was sustained, with full remission of jaundice.

\section{CASE 4}

A 78-year-old man was admitted to hospital with severe congestive heart failure of unknown cause, having suffered increasing shortness of breath for two weeks. On examination there was gross oedema, jugular venous pressure of $+6 \mathrm{~cm}$, and cardiac
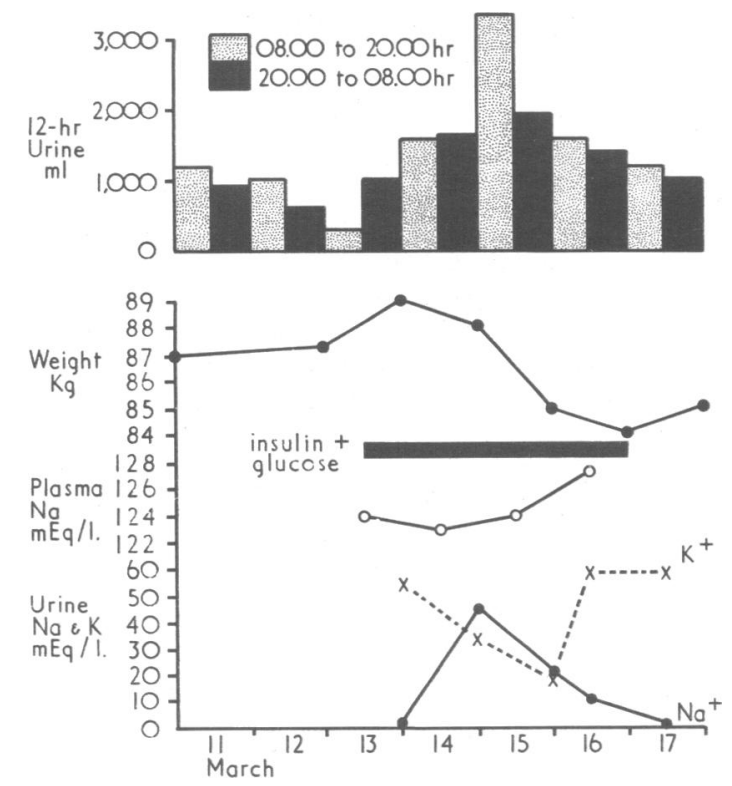

FIG. 5-Case 4. Changes in weight, urine output, and electrolyte levels in plasma and urine in response to insulin and glucose infusion.

enlargement. The pulse was regular at $110 / \mathrm{min}$. In spite of spironolactone $100 \mathrm{mg}$ and frusemide $500 \mathrm{mg}$ daily he continued to deteriorate and to gain weight (see Fig. 5). His blood urea rose to $116 \mathrm{mg} / 100 \mathrm{ml}$. Late on $13 \mathrm{March}$ insulin, glucose, and potassium infusion was started in addition to the diuretics and continued for four days. A sodium and water diuresis ensued with a rise in plasma sodium from 123 and $127 \mathrm{mEq} / 1$. In spite of an increased potassium intake there was a fall in urinary potassium excretion. His blood urea fell to $44 \mathrm{mg} / 100 \mathrm{ml}$. He felt much better and his appetite returned, but unfortunately two weeks later he deteriorated again and became unresponsive to insulin therapy.

\section{CASE 5}

A 59-year-old man with chronic rheumatic heart disease had a mitral valve replacement in April 1971. Postoperatively he continued in severe congestive failure. Ethacrynic acid $200 \mathrm{mg}$ daily and spironolactone $150 \mathrm{mg}$ daily produced a very slow improvement and he was eventually discharged. He was readmitted in October with gross congestive failure, hyponatraemia, and resistance to diuretics. At this time plasma urea was $96 \mathrm{mg} / 100 \mathrm{ml}$ sodium, $120 \mathrm{mEq} / 1$., and potassium $4.2 \mathrm{mEq} / 1$. An insulin, glucose, and potassium infusion was given on two successive days with no clinical response and a fall in plasma sodium to 116 $\mathrm{mEq} / 1$. He died a few days later.

\section{CASE 6}

A man, aged 41, who had chronic rheumatic heart disease was admitted to hospital with gross congestive heart failure. He had mitral, aortic, and tricuspid incompetence and had been deteriorating over the previous few months. On admission he had gross oedema, jugular venous pressure of $15 \mathrm{~cm}$ above the sternal angle, liver enlargement, and jaundice. Plasma urea was $86 \mathrm{mg} /$ $100 \mathrm{ml}$, sodium $118 \mathrm{mEq} / 1$., and potassium $4.3 \mathrm{mEq} / 1$. He remained unresponsive to frusemide, ethacrynic acid, and spironolactone. An insulin, glucose, and potassium infusion over 12 hours produced no response, no rise in urine output, and a fall in plasma sodium to $115 \mathrm{mEq} / 1$. The infusion was abandoned and he died 12 hours later.

\section{Discussion}

The results of treatment with insulin, glucose, and potassium infusion described here suggest that it may be a useful adjunct to therapy in some patients. The fact that no response was obtained in two cases is less important than the striking success in others, particularly since conventional therapy had been considered by other physicians to have failed. It also seems from this small study that sensitivity to this form of treatment is apparent within 24 hours, and it is pointless to persist if no benefit has been seen in this time. It seems likely to be of most benefit in those patients with a history of rapid deterioration over a short period of time, in those being prepared for cardiac surgery, and also during the postoperative period (Gautam, 1969).

The mechanism of action of insulin in heart failure is probably that postulated by Flear (1966) and suggested by Hinton and Allison (1969) in burnt patients. It has been shown that insulin promotes rapid extrusion of sodium from skeletal muscle cells in vitro (Zierler, 1966; Kernan, 1962). There is evidence that in states such as heart failure and injury there is an increased "leakiness" of cell membranes to sodium, so that a high intracellular level of sodium, chloride, and water is present (Flear, 1966; Hinton and Allison, 1969). This change impairs the activity of cells, including myocardial cells. The rise in plasma sodium concentration (the values were checked in triplicate) during the six hours of infusion in Cases 2 and 3 cannot be explained on the grounds of water loss. Changes in plasma sodium must be related to changes in total body water (Wynn and Rob, 1954), for an increase in extracellular sodium concentration causes passage of water from the intracellular space to maintain osmotic equilibrium. In normal lean patients the total water may be calculated as $60 \%$ of the body weight. This assumption is used here even though it is probably an underestimate of body water in patients with heart failure. In Case 2 a rise in plasma sodium from 121 to $128 \mathrm{mEq} / \mathrm{l}$. would require a net gain of $265 \mathrm{mEq}$ of sodium or a loss of $2 \cdot 2$ litres of water. Since the weight loss over this six-hour period was $1.6 \mathrm{~kg}$ and the net sodium loss in urine was $84 \mathrm{mEq}$ there was a negative water balance relative to sodium of $900 \mathrm{ml}$. There is a discrepancy therefore of 1.3 litres. 
A similar calculation may be made in Case 3, where there was a rise in plasma sodium from 123 to $131 \mathrm{mEq} / \mathrm{l}$. over a six-hour infusion period with a fall in weight from 68 to $67.9 \mathrm{~kg}$ and a urinary sodium loss of $50 \mathrm{mEq} / 1$. The discrepancy in this case is 2.8 litres. It is difficult therefore to escape the conclusion that sodium passed from the intracellular to the extracellular space during the treatment period. A rapid and direct action of the treatment on the myocardium is also suggested by the change of rhythm seen within an hour of starting the infusion in Cases 1 and 2 and the rapid recovery from cardiogenic shock in Case 1. It could be argued that some of the improvement seen in these patients was due to potassium gain. This is unlikely in view of the rapidity of response long before any substantial positive potassium balance could be achieved. In those patients who responded biochemically there was also a clinical improvement with an increase in appetite and feeling of well-being. Although such changes are difficult to express quantitatively they were a striking and not unimportant feature of the response to treatment.

We wish to thank Dr. G. Walters and Dr. R. D. Eastham for the biochemical estimations performed in their laboratories at the Bristol Royal Infirmary and Frenchay Hospital. We also thank Dr. J. E. G. Pearson, Dr. D. W. Barritt, and Dr. S. C. Jordan for permission to study patients under their care. We are grateful to Dr. M. Hartog and Professor A. E. Read for help and encouragement during this study. The support of the Wellcome Trust for one of us (S.P.A.) is gratefully acknowledged.

Requests for reprints should be addressed to Dr. S. P. Allison, Nottingham General Hospital, Nottingham NGl 6HA.

\section{References}

Flear, C. T. G. (1966). Electrolytes and Cardiovascular Diseases, ed. E. Bajusz, vol. 2, p. 357. Basle, Karger.

Gautam, H. P. (1969). Lancet, 1, 1315.

Hinton, P., and Allison, S. P. (1969). Lancet, 2, 595

Hinton, P., Allison, S. P., Littlejohn, S., and Lloyd, J. (1971). Lancet, 1, 767.

Kernan, R. P. (1962). Fournal of Physiology, 162, 129.

Medical Research Council Working Party (1968). Lancet, 2, 1355.

Sodi-Pallares, D., Ponce de Leon, J., Bisteni, A., and Medrano, G. A. (1969). Lancet, 1, 1315 .

Wynn, V., and Rob, C. G. (1954). Lancet, 1, 587.

Zierler, K. L. (1966). American Fournal of Medicine, 40, 735.

\section{PRELIMINARY COMMUNICATIONS}

\section{Glucose and Insulin Metabolism after Pancreatic Transplantation}

\author{
R. A. SELLS, R. Y. CALNE, V. HADJIYANAKIS, \\ V. C. MARSHALL
}

British Medical fournal, 1972, 3, 678-681

\section{Summary}

After removal of the pancreas pigs develop hyperglycaemia and ketosis. Both orthotopic and heterotopic transplants prevent hyperglycaemia but the animals so treated display markedly different patterns of glucose and insulin metabolism. Orthotopic graft recipients have normal glucose tolerance curves with raised plasma insulin levels. The glucose tolerance curves of heterotopic graft recipients show significant hypoglycaemia and very marked hyperinsulinaemia. These results are explicable by the diversion of the two pancreatic hormones from the liver, and possibly by the effect of ischaemia and denervation on the pancreas.

\section{Introduction}

Insulin has remained the mainstay of treatment in human diabetes since its discovery 50 years ago. Although insulin prolongs life in insulin-dependent diabetics, the long-term features of the disease and its complications may not be pre-

Department of Surgery, University of Cambridge

R. A. SELLS, F.R.C.S., Assistant Director of Research (Present appointment: Senior Lecturer, Department of Surgery, University of Liverpool)

R. Y. CALNE, F.R.C.S., Professor of Surgery

V. HADJIYANAKIS, M.D., Visiting Research Fellow (Present address: Neon Phychikon, Athens, Greece)

V. C. MARSHALL, F.R.C.S., Visiting Research Fellow (Present address: Department of Surgery, Royal Melbourne Hospital, Parkville, Victoria 3052, Australia) vented. "Control" of glucose metabolism in insulin-dependent diabetics may be complicated by neutralizing antibodies to heterologous insulin injections produced in the recipient (Burson and Yalow, 1960). Furthermore, the injection of a single dose of a "depot" insulin results in a period when the hormone is released at a steady rate into the circulation, a situation which requires rigid dietary control to prevent hypoglycaemia. In short, exogenous insulin therapy can produce enough hormone for day-to-day needs but cannot replace the delicately and homoeostatically balanced secretion of insulin (present in the normal subject and absent in the insulin-dependent diabetic) which controls the level of circulating glucose in accordance with the body's needs.

Pancreatic grafts may temporarily restore to normal the glucose metabolism of animals rendered diabetic experimentally (De Jode and Howard, 1962; Reemstma et al., 1964; Bergan et al., 1965; Largrader, 1967; Mitchell and Davidson, 1967) and patients suffering from maturity onset or juvenile diabetes (Lillehei et al., 1967; Lillehei et al., 1970). Although the side effects of immunosuppression make the procedure unjustifiable in most cases it is likely that with improved methods of suppressing graft rejection pancreatic grafting may well become a useful therapeutic tool in the treatment of diabetes, particularly if improved control of carbohydrate metabolism can be shown to influence the chronic retinal, neurological, and vascular side effects of the disease. Meanwhile more information is required on the metabolic effects of the types of graft available.

Pancreatic grafts may be inserted heterotopically or orthotopically. In the heterotopic graft pancreatic venous blood drains into a systemic vein and therefore bypasses the liver; orthotopic grafts drain into the portal vein, whence the route of delivery of insulin and glucagon to the liver is normal. This paper presents a comparison of the glucose and insulin metabolism in apancreatic pigs after these two procedures.

\section{Animals}

Large white Landrace or large white/Landrace (cross) pigs weighing 10-35 kg were used. These were obtained from the Agricultural Research Centre's pig colony at Babraham, 